\title{
Development of a Conceptual Model of Chronic Hand Eczema (CHE) Based on Qualitative Interviews with Patients and Expert Dermatologists
}

\author{
Laura Grant · Lotte Seiding Larsen - Kate Burrows · Donald V. Belsito • \\ Elke Weisshaar · Thomas Diepgen · Julie Hahn-Pedersen • \\ Ole E. Sørensen · Rob Arbuckle
}

Received: September 23, 2019 / Published online: January 19, 2020

(C) The Author(s) 2020

\begin{abstract}
Introduction: Chronic hand eczema (CHE) is a relapsing inflammatory dermatologic disease. Signs and symptoms can have a significant impact on patients' health-related quality of life (HRQoL). The aim of this study is to characterize the core signs, symptoms and impacts of CHE to develop a conceptual model.

Methods: A structured literature search and qualitative interviews with 20 adult $\mathrm{CHE}$
\end{abstract}

Enhanced Digital Features To view enhanced digital features for this article go to https://doi.org/10.6084/ m9.figshare.10329293.

L. Grant · K. Burrows ( $ه) \cdot$ R. Arbuckle

Adelphi Values, Adelphi Mill, Grimshaw Lane,

Bollington, Cheshire, UK

e-mail: Kate.Burrows@Adelphivalues.com

L. Grant

e-mail: laura.grant@Adephivalues.com

L. Seiding Larsen · J. Hahn-Pedersen · O. E. Sørensen LEO Pharma A/S, Industriparken 55, 2750 Ballerup, Denmark

D. V. Belsito

Columbia University Medical Center, 16th St \& Broadway, New York, NY 10027, USA

E. Weisshaar · T. Diepgen

University Hospital Heidelberg, Im Neuenheimer

Feld 672, 69120 Heidelberg, Germany patients in the US and 5 expert dermatologists were conducted to explore the patient experience of CHE signs, symptoms and impacts. Findings were used to support the development of a conceptual model.

Results: There was a paucity of CHE qualitative research in the literature, supporting the need for the prospective qualitative research. The primary signs and symptoms identified from the literature review and interviews included itch, dryness, cracking, pain, thickened skin and bleeding. The most salient impacts included embarrassment and appearance concerns, frustration, impacts on work and sleep disturbance. Saturation was achieved for all signs, symptoms and impact concepts.

Conclusions: Findings from this literature review and in-depth qualitative interviews supported the development of a comprehensive conceptual model documenting the signs, symptoms and impacts relevant to $\mathrm{CHE}$ patients. Such a model is of considerable value given the lack of existing studies in the literature focused on the qualitative exploration of the CHE patient experience. Limitations included the patient sample being only from the US and not including some CHE subtypes.

Keywords: Adult; Chronic hand eczema; Conceptual model; Hand eczema; Healthrelated quality of life; Impact; Interview; Literature review; Qualitative research; Symptom 
Key Summary Points

The signs and symptoms of chronic hand eczema (CHE) have a substantial impact on patients' daily lives and physical functioning.

A qualitative literature and instrument review identified a paucity of qualitative literature in CHE.

Subsequently, qualitative interviews with CHE patients and expert dermatologists were conducted to support the development of a comprehensive conceptual model in CHE.

\section{INTRODUCTION}

Hand eczema (HE), also known as hand dermatitis, is a relapsing, chronic, inflammatory disease that may often become chronic and affects approximately $10 \%$ of the population across the EU and North America [1]. HE is defined as chronic (chronic hand eczema-CHE) when symptoms persist $>3$ months or the symptoms return twice or more within 12 months [2].

$\mathrm{HE}$ is characterized by signs of erythema, vesicles, papules, scaling, fissures, hyperkeratosis, pruritus and pain and can affect one or both dorsal hands and palms. Predisposing endogenous and external factors play a part in the development of HE. Excessive, direct contacts with water or soap, harsh chemicals, specific allergens, mild toxic agents or irritants are the major predisposing factors responsible for the onset of HE [3]. Consequently, the risk of HE is higher in occupational groups where individuals have contact with chemical and other irritants (e.g., catering, cleaning, healthcare and mechanical occupations) [4]. HE can develop in childhood but onset is most common among working-age adults [5]. HE severely impacts patients' health-related quality of life (HRQoL) and causes significant psychologic and social distress [6]. HE can be classified according to its etiology into three key subtypes known as irritant, allergic or atopic; however, mixed forms of subtypes are common [2, 7]. Hyperkeratotic and vesicular subtypes have also been identified to represent distinct clinical subtypes [8]. Although sometimes challenging to differentiate, HE is widely accepted and recognized as a distinct disease from other dermatologic disorders $[2,9]$.

The purpose of this qualitative study was to explore and document the patients' symptom experience of CHE and impact on HRQoL through review of the literature and qualitative research with patients in the US and expert dermatologists. A second objective was to use the findings to iteratively develop a conceptual model covering the different CHE subtypes to illustrate the patient experience of CHE.

\section{METHODS}

Three different research activities were performed: a qualitative literature and instrument review, qualitative interviews with expert dermatologists and adult CHE patients. This article is based on previously conducted studies and does not contain any studies with human participants or animals performed by any of the authors. This study was reviewed and approved by Copernicus IRB (reference ADE1-17-162).

\section{Literature Review}

A targeted, structured literature search was conducted to identify core signs/symptoms and impacts of CHE. Searches were conducted in April 2018 and limited to articles published in English, concerning human subjects and published between 2007 and April 2018 using the search terms outlined in Table 1.

Published, peer-reviewed articles were identified via title and abstract searches in electronic bibliographic databases: MEDLINE, Embase and PsycINFO. Disease (i.e., hand eczema, chronic hand eczema, hand dermatitis), and qualitative research (i.e., thematic analysis, interviews, focus groups) MESH terms or key words were combined in a search strategy using Boolean logic commands (OR and AND). A supplementary manual search was conducted in Google 
Table 1 Search string for qualitative literature and instrument review

\begin{tabular}{ll}
\hline $\begin{array}{l}\text { Search } \\
\text { number }\end{array}$ & Search terms \\
\hline 1 & Hand eczema or hand dermatitis or hand dermatoses or (dermatis ADJ2 hand) \\
2 & Hand dermatoses/use PPEZ \\
3 & Hand eczema/ \\
4 & 1 or 2 or 3 \\
5 & Qualitative or interviews or focus groups or ethnographs or patient experience or lived experience or \\
6 & phenomenolos or thematic analysis or content analysis or grounded theory \\
7 & Measures OR questionnaires OR instruments OR (patient ADJ reported ADJ outcomes) \\
8 & 5 OR 6 \\
9 & 4 AND 7 \\
10 & Duplicates removed \\
\hline
\end{tabular}

Scholar to ensure all key/recently published articles were captured. A supplementary review of internet-based patient blogs and forums was conducted to identify naturalistic data directly from patients [10, 11]. Specific inclusion and exclusion criteria and formal ranking criteria were established at the beginning of the process to identify relevant material for review and to ensure rigor and consistency in the screening process. These criteria were focused on identifying articles that include qualitative research in patients with CHE or, failing that, at least seemed likely to describe the signs, symptoms and impacts of HE. The electronic database search resulted in the generation of an initial pool of 503 articles. The titles and abstracts were then reviewed according to the pre-defined ranking criteria (Table 2 ).
Articles selected for full text review based on review of titles and abstracts were evaluated, and salient information (particularly direct patient quotes) pertaining to study aim(s), sample demographics, methodology and results were extracted and summarized. From the extracted information, key concepts relating to CHE signs/symptoms and associated impacts were identified and used to develop a preliminary conceptual model outlining the patient experience of CHE. An overview of the screening process is presented in Fig. 1.

\section{Concept Elicitation Interviews}

Interviews were conducted with US CHE patients $(n=20)$ and expert dermatologists

Table 2 Qualitative literature review article ranking criteria

\begin{tabular}{ll}
\hline Rank & Criteria \\
\hline 1 & Article describes qualitative research (e.g., patient interviews or focus groups) in patients with CHE \\
2 & Article describes qualitative research (e.g., patient interviews or focus groups) in patients with HE \\
& Article describes non-qualitative research (e.g., instrument development) in patients with CHE \\
3 & Article mentions HE but not in relation to symptoms, impacts or the patient experience \\
Exclude & Article has relevant terms in background or as an implication in the discussion of the article \\
\hline
\end{tabular}




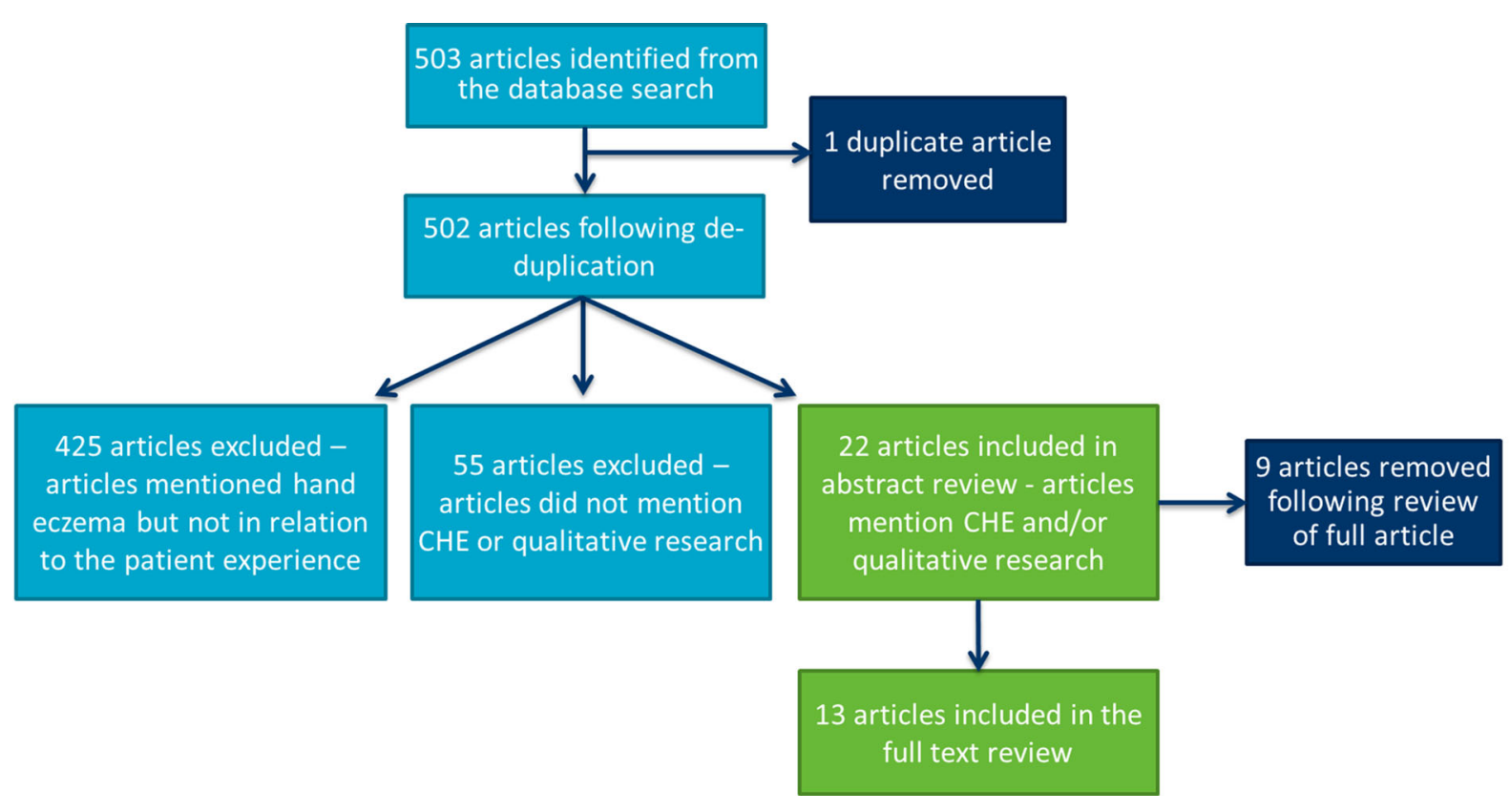

Fig. 1 Overview of literature article screening process

$(n=5)$ from both the US and Europe by expert qualitative interviewers.

\section{Patient Interviews}

Face-to-face, semi-structured patient interviews were performed between May 2017 and April 2018. Patients were recruited through primary care physicians and dermatologists. Patients were required to be at least 18 years old and have a clinician-confirmed diagnosis of $\mathrm{CHE}$ defined according to the guideline on the management of hand eczema (ICD-10 codes: L20. L23. L24. L25. L30) [2]. Quotas were used to ensure that the sample included patients with different levels of disease severity according to a standardized physician global assessment (PGA), although it must be noted that no training was provided on the completion of the PGA.

Patients were recruited from five different geographical locations in the US given that exposures to allergens can differ according to geographical and seasonal factors. Quotas were employed to recruit a mix of the three most frequent subtypes (allergic, irritant, atopic) [12] to ensure a variety of patient perspectives were obtained and the broad population was fully understood. The quotas did not require that any of the patients should be currently having a 'flare' but the qualitative discussion during the interviews made clear that many patients had recently had a flare.

\section{Expert Dermatologist Interviews}

To gain a clinical perspective of the patient experience, semi-structured telephone interviews were conducted between June 2017 and March 2018 with five expert dermatologists from the US $(n=2)$, Germany $(n=2)$ and Denmark $(n=1)$ who were involved in the care, treatment and research of individuals with CHE. The conceptual model was updated accordingly.

\section{Interview Methodology}

Ethical approval was provided by Copernicus, a US centralized Independent Review Board, and written informed consent was obtained from all patients. Interviews were conducted in two rounds $(n=10)$, allowing modifications to the interview guide between rounds. The changes made are outlined in Table 3. 
Table 3 Description of changes made between the two rounds of interviews

\begin{tabular}{|c|c|}
\hline Change & Rationale \\
\hline Flare-ups & $\begin{array}{l}\text { Patients frequently discussed flare-ups and periods of symptoms exacerbation } \\
\text { during the interviews. It was therefore important in the second round of } \\
\text { interviews to ascertain whether patients experience symptoms outside of such } \\
\text { flare-ups or whether symptoms are typically confined to these periods }\end{array}$ \\
\hline Sign and symptom overlap & $\begin{array}{l}\text { Several of the signs/symptoms reported (in both the literature review and patient } \\
\text { interviews) seem to be closely related or overlapping conceptually. It was } \\
\text { therefore important in the second round of interviews to identify whether these } \\
\text { are distinct concepts or whether it would be possible to consider them } \\
\text { synonymous }\end{array}$ \\
\hline $\begin{array}{l}\text { Itch and scratching as the cause of } \\
\text { secondary symptoms }\end{array}$ & $\begin{array}{l}\text { Itch was reported as the cardinal symptom during the initial patient interviews, and } \\
\text { many other symptoms were discussed as being related and secondary to itching } \\
\text { and scratching. It was important to establish the extent to which other symptoms } \\
\text { are inherently part of the disease or simply a result of excessive scratching }\end{array}$ \\
\hline Symptom: heat & $\begin{array}{l}\text { Heat was reported by } 7 / 10 \text { patients in the first round of interviews and seemed to } \\
\text { be described slightly differently from burning. Thus, it was explored in further } \\
\text { detail in the remaining interviews in an attempt to establish whether heat, } \\
\text { burning and tingling are descriptions of the same sensation or can be considered } \\
\text { distinct }\end{array}$ \\
\hline Impact: movement/holding objects & $\begin{array}{l}\text { Restricted movement of the hands and fingers was identified in the literature } \\
\text { review, and two patients also discussed being unable to hold objects because of } \\
\text { swelling in the first round of interviews. This concept was thus explored in } \\
\text { further detail in the remaining patient interviews }\end{array}$ \\
\hline Impact: intimate relationships & $\begin{array}{l}\text { This impact was discussed in the expert dermatologist interviews as a relevant } \\
\text { impact of CHE, and so it was agreed to probe on this separately rather than } \\
\text { grouped under family life. The expert dermatologists indicated that any activities } \\
\text { involving 'touching others' can be impacted, and this was explored further in the } \\
\text { second round of interviews }\end{array}$ \\
\hline
\end{tabular}

\section{Qualitative Analysis}

Qualitative analysis of verbatim transcripts involved sorting quotes by conceptual domain using thematic analysis methods and computerassisted qualitative data analysis software, ATLAS, Ti [13]. Using an inductive-deductive approach, a code list was developed iteratively and updated dynamically as further data were analyzed [14]. Quotes relating to CHE symptoms and impacts were grouped, and codes were organized into higher order domains. Saturation was assessed to evaluate the adequacy of the qualitative sample size $[15,16]$.

\section{RESULTS}

\section{Results of the Literature Review}

The literature searches generated 503 abstracts. Titles and abstracts were reviewed according to pre-defined ranking criteria, and the 13 most relevant articles were selected for full-text review; these articles included direct patient quotes or provided descriptions of symptoms and impacts directly from patients. One qualitative article [17] and 12 non-qualitative articles were reviewed [12, 18-28], and the findings 
were supplemented by data from six internet sources (blogs and forums). The 13 articles documented research studies conducted with individuals with $\mathrm{HE}$ and/or CHE reporting patients' signs/symptoms and impacts.

Twenty-two signs/symptoms were identified from the literature and internet sources. Based on these findings, a preliminary conceptual model of the patient experience of CHE was developed.

\section{Results of Qualitative Interviews with Expert Dermatologist and Patients}

\section{Demographic and Clinical Characteristics}

The five dermatologists interviewed included four academic professors/dermatologists and one specialist in dermatologic immunity. Among them were authors DVB, TD and EW. Mean time in practice was 27.2 years (range 15-35 years).

The sample of 20 patients included a broad age range (19-71 years), and approximately two-thirds were female $(n=13,65 \%)$, which reflects the typical prevalence for CHE (Table 4) $[19,29,30]$. A range of CHE subtypes was represented in the sample; atopic $(n=9,45 \%)$, allergic $(n=4,20 \%)$ and irritant $(n=7,35 \%)$. Patients' severity of disease, as rated by the physician global assessment (PGA) tool, was recorded as mild $(n=5,25 \%)$, moderate $(n=9$, $45 \%)$ and severe $(n=6,30 \%)$, and time since diagnosis ranged from $<1$ to $>15$ years.

\section{Concept Elicitation Findings: Signs and Symptoms}

\section{Patient Interview Findings}

Thirty signs/symptoms associated with CHE were reported by the patients. Of note, not all patients were asked about every single symptom as only signs/symptoms and impacts identified in the literature were included in the interview guide. Any concepts spontaneously reported during the patient interviews were then added to the interview guide for probing in subsequent interviews. It was notable that the signs/ symptoms of itch, burning, redness and dry skin were reported by almost all patients spontaneously and few patients based on probed questioning (Table 5). For the remaining signs/symptoms there was more of a split between spontaneous and probed reporting, suggesting they may be slightly less impactful/ salient for patients. These findings are consistent with the findings of the qualitative literature review. The most frequently reported signs/ symptoms included itch $(n=20)$ $[12,17,18,27,28,31]$, redness $(n=20)$ $[18,19,28]$, cracked skin $(n=19)[17-19,28]$, dry skin $(n=18)[18,28]$, painful skin $(n=18)$ $[17,18,28]$, rough skin $(n=17)$, thick skin $(n=17)$ [28], swelling $(n=16)$ [19] and bleeding $(n=15)$ [18]. Saturation analysis indicated saturation was achieved for all of the signs/symptoms in patients with CHE.

All patients described CHE as a 'flaring' disease, characterized by episodes or periods when symptoms are worse than others, with symptoms perceived to be worsened by numerous triggers including: exposure to various allergens and/or chemicals ( $n=10,50 \%)$, cold temperatures $(n=9,45 \%)$, warm temperatures $(n=4$, $20 \%)$, excessive hand washing $(n=3,15 \%)$ and stress $(n=2,10 \%)$. The signs/symptoms were reported to be either non-existent or much less severe between flare-ups. It was notable that inflammatory signs/symptoms such as itch, painful skin, red skin, swelling and burning were more frequently associated with a flare-up, whereas signs/symptoms such as dry skin, thick skin and flaking were reported to be experienced mostly during a flare, but also often between flares or immediately after a flare-up.

The majority of patients also discussed their signs/symptoms of CHE in relation to one another; many of the signs/symptoms were described as presenting at the same time or as a direct consequence of another sign or symptom. Itching was the symptom most commonly reported to be related to other symptoms, and several symptoms were often described as being a consequence of scratching because of the itch (e.g., bleeding, erythema, flaking). Cracking was also frequently described as causing secondary symptoms such as bleeding and pain. Other symptoms were typically reported as occurring simultaneously (e.g., dryness and flaking, thickening and roughness). The different CHE 
Table 4 Demographic characteristics

\begin{tabular}{|c|c|}
\hline Demographic characteristic & $\begin{array}{l}\text { Number of patients } \\
(N=20)\end{array}$ \\
\hline \multicolumn{2}{|l|}{ Sex, $n(\%)$} \\
\hline Male & $7(35 \%)$ \\
\hline Female & $13(65 \%)$ \\
\hline \multicolumn{2}{|l|}{ Age } \\
\hline Mean (standard deviation) & $45(13)$ \\
\hline Range & $19-71$ \\
\hline \multicolumn{2}{|l|}{ Ethnicity, $n(\%)$} \\
\hline Hispanic or Latinx & $0(0 \%)$ \\
\hline Non-hispanic or Latinx & $20(100 \%)$ \\
\hline \multicolumn{2}{|l|}{ Race, $n(\%)$} \\
\hline Caucasian & $13(65 \%)$ \\
\hline Black/African American & $6(30 \%)$ \\
\hline Multiracial & $0(0)$ \\
\hline Asian or Pacific Islander & $1(5 \%)$ \\
\hline Native American/Alaska native & $0(0 \%)$ \\
\hline North African/Middle Eastern & $0(0 \%)$ \\
\hline Other & $0(0 \%)$ \\
\hline \multicolumn{2}{|l|}{ Work status, $n(\%)$} \\
\hline Working full or part time & $14(70 \%)$ \\
\hline Retired & $3(15 \%)$ \\
\hline Full time homemaker & $1(5 \%)$ \\
\hline Unemployed & $1(5 \%)$ \\
\hline $\begin{array}{l}\text { Not working because of } \\
\text { medical condition }\end{array}$ & $1(5 \%)$ \\
\hline Other & $0(0 \%)$ \\
\hline \multicolumn{2}{|l|}{ * Occupation, $n=13$ (\%) } \\
\hline Office/administration work & $4(31 \%)$ \\
\hline Manual work & $6(46 \%)$ \\
\hline Unspecified & $3(23 \%)$ \\
\hline \multicolumn{2}{|l|}{ Highest level of education, $n$ (\%) } \\
\hline Some high school & $0(0 \%)$ \\
\hline Completed high school & $7(35 \%)$ \\
\hline
\end{tabular}

Table 4 continued

\begin{tabular}{ll}
\hline Demographic characteristic & $\begin{array}{l}\text { Number of patients } \\
(\boldsymbol{N}=\mathbf{2 0})\end{array}$ \\
\hline Some years of college & $10(50 \%)$ \\
University/college degree & $3(15 \%)$ \\
\hline
\end{tabular}

${ }^{*}$ Office/administration work included data entry and sales roles, while manual occupations included hairdressers, factory workers, food servers, etc.

signs/symptoms varied in the different regions of the hand where they were typically experienced; for example, itchy skin, swelling and dry skin were most frequently reported to be experienced on the palms, whereas cracked skin was most frequently reported to be experienced in the interdigital regions. Subgroup analyses confirmed the relevance of core symptoms across irritant, allergic and atopic subtypes, with all signs/symptoms reported by patients of all subtypes.

\section{Expert Dermatologist Findings}

The signs/symptoms described by the expert dermatologists were highly consistent with those of patients. Lesions and sores/cuts were the only concepts that emerged from the expert dermatologist interviews but were not reported by any patients.

While the expert dermatologists and patients largely referred to the same signs/symptoms, the terminology used to describe such signs/ symptoms differed, as expected (e.g., redness referred to as 'erythema' and thickness as 'lichenification').

Reports from patients and expert dermatologists supported distinguishing CHE as its own distinct disease separate from other dermatologic diseases. The experts provided insight into differences in presentation and diagnosis of CHE compared with other dermatologic conditions [i.e., atopic dermatitis (AD) and psoriasis]. The experts also described a difference in age of onset (with $\mathrm{AD}$ typically diagnosed in childhood whereas CHE is not commonly diagnosed until adulthood) and clinical morphology (i.e., differences in appearance of lesions). 
Table 5 Signs and symptoms and example quotes elicited by patients with CHE $(N=20)$

\begin{tabular}{|c|c|c|c|c|}
\hline \multirow{2}{*}{$\begin{array}{l}\text { Signs/ } \\
\text { symptom }\end{array}$} & \multicolumn{3}{|c|}{ Patients $(N=20)$} & \multirow{2}{*}{$\begin{array}{l}\text { Expert } \\
\text { dermatol } \\
(N=5)\end{array}$} \\
\hline & $\overline{S^{*}}$ & $P^{* *}$ & Total & \\
\hline \multicolumn{5}{|l|}{ Symptoms } \\
\hline Itch & 19 & 1 & $20(100 \%)$ & $5(100 \%)$ \\
\hline $\begin{array}{l}\text { Painful } \\
\text { skin }\end{array}$ & 12 & 6 & $18(90 \%)$ & $5(100 \%)$ \\
\hline Burning & 13 & 0 & $13(65 \%)$ & $5(100 \%)$ \\
\hline
\end{tabular}

Example patient quotes dermatologists

$$
\text { (1) }
$$

(a)

"Like a mosquito bite maybe-like a bad bunch of them" (female aged 52 with severe CHE)

"But you wonder how it's going to heal when it's painful." (male aged 56 with moderate CHE)

"If I don't pay attention to it and I continue to do whatever I'm doing I've had it burn bad. I've had it start burning on me" (female aged 50 with severe CHE)

Signs

$\begin{array}{lcccc}\text { Redness } & 17 & 3 & 20(100 \%) & 5(100 \%) \\ \begin{array}{c}\text { Cracked } \\ \text { skin }\end{array} & 11 & 8 & 19(95 \%) & 5(100 \%)\end{array}$

"And I think the red, I scratch so much I probably do it to myself" (female aged 65 with moderate $\mathrm{CHE}$ )

"If the skin is cracking, uh, then it's really, uh-then you, you don't want to extend your hand or open your hand because that will just separate the skin a little bit more-they look like very small cuts" (male aged 56 with moderate CHE)

Dry skin $\quad 17 \quad 1 \quad 18(90 \%) \quad 5(100 \%)$

"When you can see it between my fingers and stuff, it's real white and dry" (male aged 42 with moderate CHE)

\begin{tabular}{|c|c|c|c|c|c|}
\hline $\begin{array}{l}\text { Thick } \\
\text { skin }\end{array}$ & 6 & 11 & 17 (85\%) & $4(80 \%)$ & $\begin{array}{l}\text { "Uh, it feels thick because I mean when it's cracked and everything it } \\
\text { feels, it feels heavy" (male aged } 38 \text { with moderate CHE) }\end{array}$ \\
\hline Swelling & 8 & 8 & $16(80 \%)$ & $5(100 \%)$ & $\begin{array}{l}\text { "I think my fingers get like sausages kind of" (female aged } 52 \text { with } \\
\text { severe CHE) }\end{array}$ \\
\hline Bleeding & 9 & 6 & $15(75 \%)$ & $5(100 \%)$ & $\begin{array}{l}\text { "Um, if the crack is bad enough, it will bleed" (female aged } 37 \text { with } \\
\text { severe CHE) }\end{array}$ \\
\hline Flaking & 10 & 4 & $14(70 \%)$ & $4(80 \%)$ & $\begin{array}{l}\text { "It's really fine and it's white and it's almost like dandruff" (female } \\
\text { aged } 50 \text { with severe CHE) }\end{array}$ \\
\hline $\begin{array}{l}\text { Oozing/ } \\
\text { weeping }\end{array}$ & 5 & 6 & $11(55 \%)$ & $4(80 \%)$ & $\begin{array}{l}\text { "With all that oozing_all that like heartbeat in your hand" (female } \\
\text { aged } 25 \text { with mild CHE) }\end{array}$ \\
\hline
\end{tabular}

*This column provides the number of patients who spontaneously reported each concept

${ }^{*}$ This column provides the number of patients who reported each concept only when probed by the interviewer

\section{Impacts}

In addition to the large number of signs/symptoms reported by patients, they also reported numerous ways in which CHE impacted their functioning and HRQoL (Table 6). Saturation analysis indicated saturation was achieved for all of the impact concepts reported by the patients with $\mathrm{CHE}$.

\section{Emotional Impacts}

Frustration was the most frequently reported emotional impact of $\mathrm{CHE}$, including frustration with the disease in general, with the incessant 
Table 6 HRQoL impacts and example quotes elicited by patients $(N=20)$

\begin{tabular}{|c|c|c|c|c|c|c|}
\hline \multirow[t]{2}{*}{ Domain } & \multirow[t]{2}{*}{ Sub-domain } & \multicolumn{3}{|c|}{ Patients $(N=20)$} & \multirow{2}{*}{$\begin{array}{l}\text { Expert } \\
\text { dermatologist } \\
(N=5)\end{array}$} & \multirow[t]{2}{*}{ Example quote } \\
\hline & & $S^{*}$ & $P^{* *}$ & Total & & \\
\hline Sleep disruption & & 8 & 7 & $15(75 \%)$ & $5(100 \%)$ & $\begin{array}{l}\text { "It would be falling asleep because you're, } \\
\text { you're conscious and alert of what your } \\
\text { hands are doing, you know" (female aged } \\
52 \text { with severe CHE) }\end{array}$ \\
\hline $\begin{array}{l}\text { Physical } \\
\text { functioning }\end{array}$ & Holding objects & 11 & 0 & $11(55 \%)$ & $5(100 \%)$ & $\begin{array}{l}\text { "When you carry a pen or a pencil you feel } \\
\text { uncomfortable, you know" (male aged } 63 \\
\text { with mild CHE) }\end{array}$ \\
\hline \multirow[t]{3}{*}{$\begin{array}{l}\text { Proximal daily } \\
\text { activity } \\
\text { limitations }\end{array}$} & $\begin{array}{l}\text { Avoiding } \\
\text { soaps/chemical }\end{array}$ & 15 & 0 & $15(75 \%)$ & $4(80 \%)$ & $\begin{array}{l}\text { "I have to be careful I mean with detergents } \\
\text { and soaps and stuff like that because I get } \\
\text { really dry and sore" (female aged } 65 \text { with } \\
\text { moderate CHE) }\end{array}$ \\
\hline & Domestic chores & 11 & 2 & $13(65 \%)$ & $4(80 \%)$ & $\begin{array}{l}\text { "I can't like fold clothes, because like the, } \\
\text { um, the way my skin cracks, it gets caught } \\
\text { on fabrics and things like that, so I can't } \\
\text { really do much around the house" (female } \\
\text { aged } 19 \text { with mild CHE) }\end{array}$ \\
\hline & Self-care & 7 & 5 & $12(60 \%)$ & $4(80 \%)$ & $\begin{array}{l}\text { "I put the cool water on first and I put my } \\
\text { hand like that and just let it run so that I } \\
\text { can get through the rest of my shower } \\
\text { without any itching" (female aged } 50 \text { with } \\
\text { severe CHE) }\end{array}$ \\
\hline Frustration & & 16 & 1 & $17(85 \%)$ & $5(100 \%)$ & $\begin{array}{l}\text { “Well, I mean, it's just something that's } \\
\text { aggravating, you know” (male aged } 42 \\
\text { with moderate CHE) }\end{array}$ \\
\hline \multirow{2}{*}{$\begin{array}{l}\text { Embarrassment } \\
\text { with the } \\
\text { appearance of } \\
\text { the hands }\end{array}$} & $\begin{array}{l}\text { Dislike the } \\
\text { appearance of } \\
\text { hands }\end{array}$ & 14 & 0 & $14(70 \%)$ & $3(60 \%)$ & $\begin{array}{l}\text { "It looks awful. You know, and it's just-I } \\
\text { don't know. I hide them all the time" } \\
\text { (female aged } 64 \text { with moderate CHE) }\end{array}$ \\
\hline & $\begin{array}{l}\text { Embarrassment/ } \\
\text { feeling self- } \\
\text { conscious }\end{array}$ & 12 & 4 & $16(80 \%)$ & $4(80 \%)$ & $\begin{array}{l}\text { "Well it sometimes is embarrassing. If I'm } \\
\text { out with people I'm scratching" (female } \\
\text { aged } 65 \text { with moderate CHE) }\end{array}$ \\
\hline Work & & 9 & 3 & $12(60 \%)$ & $5(100 \%)$ & $\begin{array}{l}\text { "No I still have to work. Even though it } \\
\text { hurts, I still have to work" (female aged } \\
37 \text { with severe CHE) }\end{array}$ \\
\hline
\end{tabular}

*This column provides the number of patients who spontaneously reported each concept

${ }^{* *}$ This column provides the number of patients who reported each concept only when probed by the interviewer 

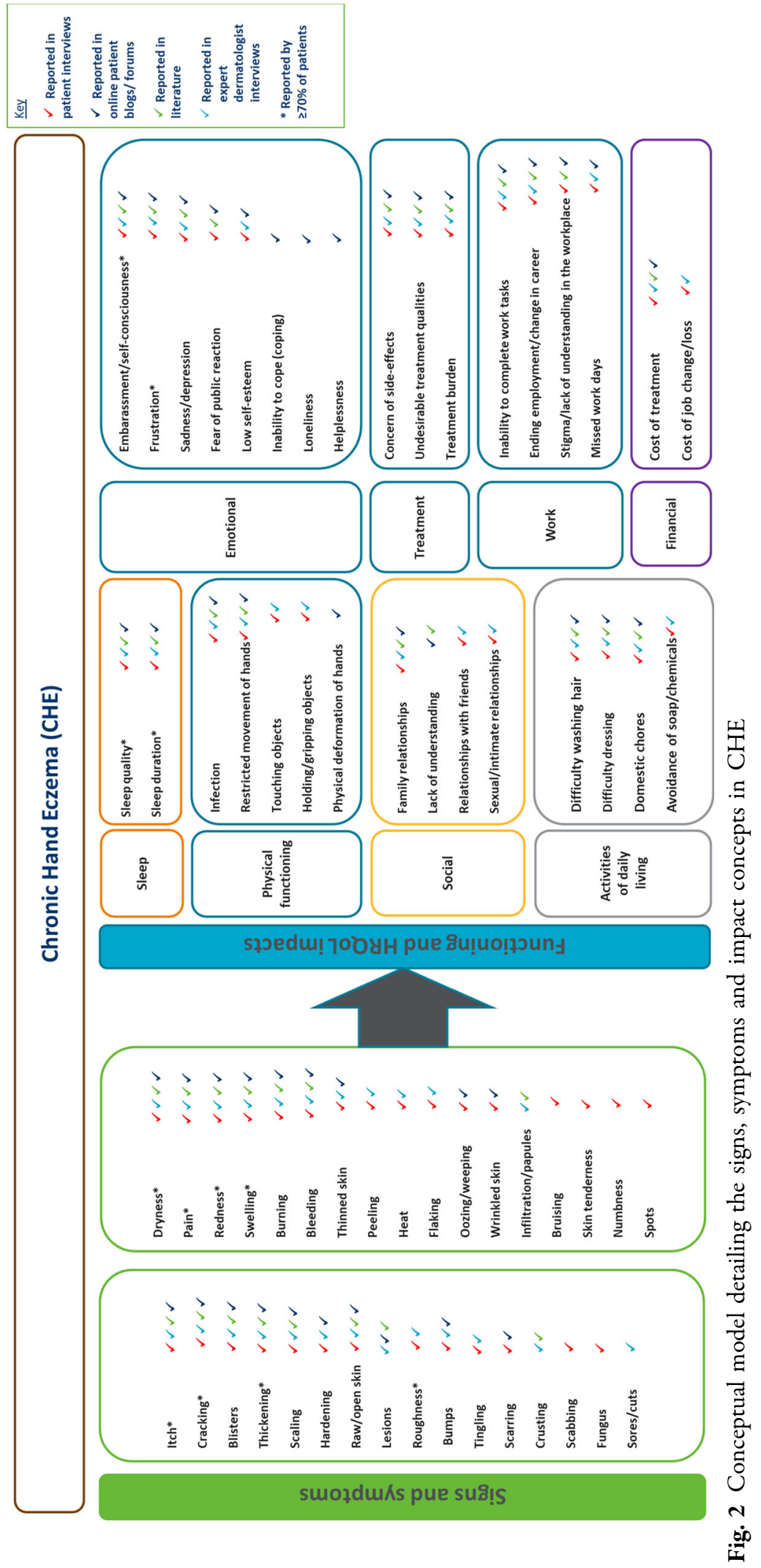
itch and with the pain. The expert dermatologists also described patients experiencing frustration due to recurrence of their signs/ symptoms. For many patients the visible signs of CHE resulted in a strong dislike of the appearance of their hands, which caused patients to feel embarrassed or self-conscious and to attempt to conceal their hands in public.

\section{Sleep Disruption}

Sleep quality was reported to be significantly impacted by the constant itching, resulting in patients having difficulty falling asleep and frequently waking up during the night. Subconscious scratching during the night commonly resulted in skin damage and more severe secondary symptoms (e.g., bleeding).

\section{Physical Impact}

Physical functioning impacts resulting from CHE included: difficulty touching objects and limitations in the movement of fingers and joints and therefore holding or gripping objects. Difficulty touching objects was due to pain, whereas difficulty holding objects was due to swelling of the hands. Avoiding certain soaps and chemicals also impacted patients' activities of daily living in terms of ability to do domestic chores (e.g., cleaning, washing-up) and wash themselves.

\section{Work and Financial Impact}

A range of work impacts associated with $\mathrm{CHE}$ were reported by the patients (including those employed in both manual and office-based occupations). Contact with allergens or increased hand washing triggers flare-ups in the more manual occupations. Patients from all occupations reported a productivity impact associated with having to take more breaks to apply topical treatments, avoiding certain activities at work or work absences. Fewer reported a financial impact associated with their work being disrupted.

\section{Conceptual Model}

The conceptual model was developed iteratively, based upon the literature, interviews with patients and dermatologists. The final conceptual model (Fig. 2) includes 33 sign and symptom concepts and 32 impact concepts organized into eight domains: sleep (2 concepts), physical functioning (5 concepts), emotional (8 concepts), social (4 concepts), daily living (4 concepts), work (4 concepts), financial ( 2 concepts) and treatment (3 concepts).

\section{DISCUSSION}

There is limited published literature on the patient experience of CHE, but it is understood to be a disease distinct from other dermatologic disorders [2]. This qualitative study aimed to explore the patient experience of CHE through review of the qualitative literature and in-depth interviews with patients and expert dermatologists. The findings were used to iteratively develop a conceptual model to illustrate the patient experience of CHE.

The literature review identified a number of signs/symptoms and impacts associated with CHE, which were subsequently used to develop a preliminary conceptual model. However, only one peer-reviewed paper reporting qualitative research (and including direct patient quotes) conducted in patients with CHE was identified [17]. In the prospective qualitative research, despite the sample of 20 patients being heterogeneous in terms of etiology [17], the descriptions of signs/symptoms experienced were found to be relatively consistent regardless of CHE subtype, sex or occupation. Consequently, a single conceptual model covering all subtypes was considered appropriate. The findings from the qualitative interviews demonstrated that patients with CHE experience a wide range of signs/symptoms: particularly itch, redness, cracking, dryness and pain. This is consistent with the literature $[12,17,23,31,32]$ and also with the concepts assessed by the main PRO measures used in HE research such as the Quality of Life in Hand Eczema Questionnaire (QOLHEQ) [33] and the Dermatology Quality of Life Index (DLQI) [34]. It was consistently reported that CHE signs/symptoms fluctuate in severity over time, with periods of worsening described as 'flare-ups.' 
The patient sample reported a range of impacts associated with $\mathrm{CHE}$, which is unsurprising given the importance of the hands for performing daily tasks and their centrality in social communication and expression. Commonly reported emotional impacts included feelings of frustration and a strong dislike of the appearance of the hands, associated with feelings of embarrassment and self-consciousness. This is supported by the literature [35], with one study finding that $89 \%$ of HE patients feel selfconscious or embarrassed by the visible signs of HE (cracking and flaking) [24]. Many patients also described their sleep being disrupted, primarily because of the itch. Perhaps surprisingly, the proportion of patients who reported having had to change their job because of their CHE was relatively low compared with the literature or the comments of the expert dermatologists, which may have been due to patients' inability to change occupation $[12,19]$. Such findings may also be explained by similar results from a more recent study evaluating the prevalence of "presenteeism" (attending work despite ill health, which should prompt rest and absence), found to be common in patients with severe HE [36].

\section{Study Limitations}

The literature review was a structured but not a 'systematic' review, and thus a future systematic review could increase confidence in the findings and enable future replication. As such, it's possible that relevant articles could have been missed (although the limited literature in CHE reduces the likelihood of that), and the findings may be more susceptible to bias as a consequence of streamlining the review process. The documented inclusion and exclusion criteria and structured ranking process aimed to ameliorate the risk of such bias, but it should be recognized that this limitation increases the risk of inappropriate conclusions being drawn. There would be value in corroborating the findings reported here through further qualitative research in other countries. Furthermore, although quota sampling resulted in a diverse sample with good representation of the three most common subtypes of CHE [12], it may prove valuable to conduct further interviews with patients with different subtypes (e.g., vesicular, hyperkeratotic-rhagadiform). Moreover, in the present research there was no quota for the inclusion of patients who were currently (or had recently been) in a flare; the inclusion of such a quota could enhance the insights derived from future research. While saturation was achieved, this was still a relatively small qualitative sample, and as such, corroboration of the findings in other samples is recommended.

\section{CONCLUSIONS}

To the best of the authors' knowledge, this is the first study to present a comprehensive conceptual model of the signs, symptoms and impacts of CHE. This study supports and expands on themes reported in the literature and assessed by existing patient-reported outcome instruments used in CHE to capture the signs, symptoms and impacts of the condition. Conceptual saturation of the data suggest that the collection of further data would be unlikely to add concepts or additional insights. As such, it's reasonable to conclude that the findings provide a comprehensive account of the CHE disease experience. The conceptual model presented in this study may be used to identify target concepts for measurement in future clinical studies in CHE. The findings from this qualitative research study can also be used to evaluate the content validity of PRO measures in the context of use of CHE studies by ensuring that draft items are appropriate and fully measure concepts that are relevant and important for a CHE population. Such measures can be used in clinical trials and clinical practice and thus support the development of therapies and clinical management practices to improve the long-term control of CHE $[37,9]$.

\section{ACKNOWLEDGEMENTS}

The authors thank the people with CHE who participated in the interviews and provided 
valuable insight into their experience of living with this condition.

Funding. This study and the Rapid Service and Open Access Fees were fully funded by LEO Pharma Research Foundation A/S (grant no. 123).

Authorship. All named authors meet the International Committee of Medical Journal Editors (ICMJE) criteria for authorship for this article, take responsibility for the integrity of the work as a whole, and have given their approval for this version to be published.

Author Contributions. All authors contributed to the design of the study. Laura Grant, Rob Arbuckle and Kate Burrows were responsible for developing the first draft of study documents, conducting the data collection and data analysis, and contributed to the interpretation. Lotte Seiding Larsen, Julie Hahn-Pedersen and Ole E. Sørensen reviewed and contributed to the study documents and reviewed the results and contributed to the interpretation. Laura Grant, Rob Arbuckle and Kate Burrows wrote the manuscript, and all authors reviewed and revised the manuscript and have given approval for this version to be published.

Disclosures. Laura Grant was an employee of Adelphi Values, a consultancy paid by LEO Pharma A/S to conduct the study and develop the manuscript. Kate Burrows was an employee of Adelphi Values, a consultancy paid by LEO Pharma A/S to conduct the study and develop the manuscript. Rob Arbuckle was an employee of Adelphi Values, a consultancy paid by LEO Pharma A/S to conduct the study and develop the manuscript Lotte Seiding Larsen is an employee of LEO Pharma. Julie Hahn-Pedersen is an employee of LEO Pharma. Ole E. Sørensen is an employee of LEO Pharma. Donald V. Belsito received payment as a consultant for engagement in the research as a clinical expert. Elke Weisshaar received payment as a consultant for engagement in the research as a clinical expert. Thomas Diepgen received payment as a consultant for engagement in the research as a clinical expert.
Compliance with Ethics Guidelines. This article is based on previously conducted studies and does not contain any studies with human participants or animals performed by any of the authors. This study was reviewed and approved by Copernicus IRB (reference ADE1-17-162).

Data Availability. Data generated from this study are not publicly available; additional data may be provided by the authors on reasonable request.

Open Access. This article is distributed under the terms of the Creative Commons Attribution-NonCommercial 4.0 International License (http://creativecommons.org/licenses/ by-nc/4.0/), which permits any noncommercial use, distribution, and reproduction in any medium, provided you give appropriate credit to the original author(s) and the source, provide a link to the Creative Commons license, and indicate if changes were made.

\section{REFERENCES}

1. Diepgen TL, Agner T, Aberer W, Berth-Jones J, Cambazard F, Elsner $\mathrm{P}$, et al. Management of chronic hand eczema. Contact Dermat. 2007;57(4): 203-10.

2. Diepgen TL, Elsner P, Schliemann S, Fartasch M, Köllner A, Skudlik C, et al. Guideline on the management of hand eczema ICD-10 Code: L20. L23. L24. L25. L30. JDDG. Journal der Deutschen Dermatologischen Gesellschaft. 2009;7:S1-15.

3. Küster D, Haufe E, Rethberg C, Bauer A, Seidler A, Schmitt J. Health utilities for controlled and uncontrolled chronic hand eczema in healthcare employees. Contact Dermat. 2018;78(1):18-27.

4. Lampel HP, Patel N, Boyse K, O’Brien SH, Zirwas MJ. Prevalence of hand dermatitis in inpatient nurses at a United States hospital. Dermatitis. 2007;18(3): 140-2.

5. Mortz C, Bindslev-Jensen C, Andersen KE. Hand eczema in the odense adolescence cohort study on atopic diseases and dermatitis (TOACS): prevalence, incidence and risk factors from adolescence to adulthood. Br J Dermatol. 2014;171(2):313-23. 
6. Sehgal VN, Srivastava G, Aggarwal AK, Sharma AD. Hand dermatitis/eczema: current management strategy. J Dermatol. 2010;37(7):593-610.

7. Cronin E. Clinical patterns of hand eczema in women. Contact Dermat. 1985;13(3):153-61.

8. Johansen JD, Hald M, Andersen BL, Laurberg G, Danielsen A, Avnstorp C, et al. Classification of hand eczema: clinical and aetiological types Based on the guideline of the Danish. Contact Dermatitis Group. Contact Dermat. 2011;65(1):13-21.

9. Donatti C, Wild D, Hareendran A. The use of conceptual models, conceptual frameworks, and endpoint models to support label claims of treatment benefit using patient reported outcomes. ISPOR Connect. 2008;14(3):9-12.

10. Heilferty CM. Toward a theory of online communication in illness: concept analysis of illness blogs. J Adv Nurs. 2009;65(7):1539-47.

11. Hillan J. Physician use of patient-centered weblogs and online journals. Clin Med Res. 2003;1(4): 333-5.

12. Cazzaniga $S$, Ballmer-Weber B, Gräni N, Spring $P$, Bircher A, Anliker M, et al. Medical, psychological and socio-economic implications of chronic hand eczema: a cross-sectional study. J Eur Acad Dermatol Venereol. 2016;30(4):628-37.

13. Hwang S. Utilizing qualitative data analysis software: a review of Atlas. ti. Soc Sci Comput Rev. 2008;26(4):519-27.

14. Joffe H, Yardley L. Content and thematic analysis. Res Methods Clin Health Psychol. 2004;56:68.

15. Sandelowski M. Sample size in qualitative research. Res Nurs Health. 1995;18(2):179-83.

16. Guest G, Bunce A, Johnson L. How many interviews are enough? An experiment with data saturation and variability. Field Methods. 2006;18(1):59-82.

17. Mollerup A, Johansen J, Thing LF. Knowledge, attitudes and behaviour in everyday life with chronic hand eczema: a qualitative study. $\mathrm{Br} \mathrm{J}$ Dermatol. 2013;169(5):1056-65.

18. Ofenloch R, Weisshaar E, Diepgen T, Apfelbacher C. Health-related quality of life in hand eczema: Itch is the most important symptom. Acta DermatoVenereologica. 2013;93(5):626.

19. Lerbaek A, Kyvik KO, Ravn H, Menné T, Agner T. Clinical characteristics and consequences of hand eczema-an 8-year follow-up study of a populationbased twin cohort. Contact Dermat. 2008;58(4): 210-6.
20. Blair HA, Scott LJ. Alitretinoin: a review in severe chronic hand eczema. Drugs. 2016;76(13):1271-9.

21. Halioua B, Aubin C, Rostain G, Mura C, Chosidow O. Does severe chronic hand eczema (sche) have differential impact on quality of life in men and women? J Am Acad Dermatol. 2015;72(5):AB78.

22. Cortesi PA, Scalone L, Belisari A, Bonamonte D, Cannavò SP, Cristaudo A, et al. Cost and quality of life in patients with severe chronic hand eczema refractory to standard therapy with topical potent corticosteroids. Contact Dermat. 2014;70(3): 158-68.

23. Apfelbacher C, Matterne U, Weiss M, Molin S, Weisshaar E, Bauer A, et al. Self-assessed disease severity is a powerful predictor of health-related quality of life in chronic hand eczema. Exp Dermatol. 2013;22(3):e23.

24. Bewley A, Mason N, Rawlins J, Walker S. An ethnographic insight into the psychological impact of hand eczema. Br J Dermatol. 2013;169:130-1.

25. Diepgen T, Purwins S, Posthumus J, Kuessner D, Augustin M. PSS14 burden of disease in patients with severe chronic hand eczema in Germany. Value Health. 2011;14(7):A504.

26. Ruiz MA, Heras F, Alomar A, Conde-Salazar L, de la Cuadra J, Serra E, et al. Development and validation of a questionnaire on'Satisfaction with dermatological treatment of hand eczema'(DermaSat). Health Qual Life Outcomes. 2010;8(1):127.

27. Apfelbacher CJ, Molin S, Weisshaar E, Bauer A, Elsner P, Mahler V, et al. Characteristics and provision of care in patients with chronic hand eczema: updated data from the CARPE registry. Acta Dermato-Venereologica. 2014;94(2):163-7.

28. Dibenedetti D, Baranowski E, Zelt S, Reynolds M, Sherrill B. Assessing United States patient and dermatologist experiences with severe chronic hand eczema. J Clin Aesthet Dermatol. 2015;8(11):19.

29. Thyssen JP, Johansen JD, Linneberg A, Menné T. The epidemiology of hand eczema in the general population-prevalence and main findings. Contact Dermat. 2010;62(2):75-87.

30. Bryld L, Hindsberger C, Kyvik K, Agner T, Menné T. Risk factors influencing the development of hand eczema in a population-based twin sample. Br J Dermatol. 2003;149(6):1214-20.

31. Ruppert L, Apfelbacher C, Molin S, Bauer A, Mahler $\mathrm{V}$, Schmitt J, et al. Itching in patients with chronic hand eczema: data from the CARPE registry. Dermatology. 2014;229(2):146-53. 
32. Mollerup A, Johansen J, Thing L. Exploring selfmanagement in chronic hand eczema-a qualitative study: P26. Contact Dermat. 2012;66.

33. Ofenloch R, Weisshaar E, Dumke AK, Molin S, Diepgen T, Apfelbacher C. The Quality of Life in Hand Eczema Questionnaire (QOLHEQ): validation of the German version of a new disease-specific measure of quality of life for patients with hand eczema. Br J Dermatol. 2014;171(2):304-12.

34. Finlay AY, Khan G. Dermatology Life Quality Index (DLQI) - a simple practical measure for routine clinical use. Clin Exp Dermatol. 1994;19(3):210-6.

35. Maccari F, Ezzedine K, Fougerousse AC, Mérhand S, Bordet $\mathrm{C}$, Jacobzone $\mathrm{C}$, et al. Building a scale for measuring burden of hand eczema: BoHEM. J Am Acad Dermatol. 2018;80:1784-5.

36. Oosterhaven JA, Flach PA, Bültmann U, Schuttelaar ML. Presenteeism in a Dutch hand eczema population-a cross-sectional survey. Contact Dermat. 2018;79:10-9.

37. Patrick DL, Burke LB, Gwaltney CJ, Leidy NK, Martin ML, Molsen E, et al. Content validityestablishing and reporting the evidence in newly developed patient-reported outcomes (PRO) instruments for medical product evaluation: ISPOR PRO Good Research Practices Task Force report: part 2 -assessing respondent understanding. Value Health. 2011;14(8):978-88. 